Letter

\title{
Potential Underestimation of Satellite Fire Radiative Power Retrievals over Gas Flares and Wildland Fires
}

\author{
Sanath Sathyachandran Kumar ${ }^{1, *} \mathbb{1}$, John Hult ${ }^{2}$, Joshua Picotte ${ }^{1}\left(\mathbb{C}\right.$ and Birgit Peterson ${ }^{3}$ \\ 1 ASRC Federal Data Solutions contractor to U.S. Geological Survey (USGS) Earth Resources Observation and \\ Science (EROS) Center, 47914 252nd Street, Sioux Falls, SD 57198, USA; jpicotte@contractor.usgs.gov \\ 2 KBR, Contractor to USGS EROS Center, Sioux Falls, SD 57198, USA; jhult@contractor.usgs.gov \\ 3 USGS EROS Center, Sioux Falls, SD 57198, USA; bpeterson@usgs.gov \\ * Correspondence: ssathyachandran@contractor.usgs.gov
}

Received: 4 December 2019; Accepted: 31 December 2019; Published: 10 January 2020

check for updates

\begin{abstract}
Fire Radiative Power (FRP) is related to fire combustion rates and is used to quantify the atmospheric emissions of greenhouse gases and aerosols. FRP over gas flares and wildfires can be retrieved remotely using satellites that observe in shortwave infrared (SWIR) to middle infrared (MIR) wavelengths. Heritage techniques to retrieve FRP developed for wildland fires using the MIR $4 \mu \mathrm{m}$ radiances have been adapted for the hotter burning gas flares using the SWIR $2 \mu \mathrm{m}$ observations. Effects of atmosphere, including smoke and aerosols, are assumed to be minimal in these algorithms because of the use of longer than visual wavelengths. Here we use Moderate Resolution Imaging Spectroradiometer (MODIS), Visible Infrared Imaging Radiometer Suite (VIIRS) and Landsat 8 observations acquired before and during emergency oil and gas flaring in eastern Saudi Arabia to show that dark, sooty smoke affects both $4 \mu \mathrm{m}$ and $2 \mu \mathrm{m}$ observations. While the $2 \mu \mathrm{m}$ observations used to retrieve gas FRP may be reliable during clear atmospheric conditions, performance is severely impacted by dark smoke. Global remote sensing-based inventories of wildfire and gas flaring need to consider the possibility that soot and dark smoke can potentially lead to an underestimation of FRP over fires.
\end{abstract}

Keywords: MODIS; VIIRS; Landsat; gas flare; fire radiative power

\section{Introduction}

Atmospheric emissions of greenhouse gases and aerosols from fires have substantial climate-forcing effects [1], and there is a need for global monitoring. Operational remote sensing-based methodologies have been developed to retrieve fire radiative power (FRP), and have been used in applications to estimate combustion/emission rates over at least the last two decades. More recently, FRP has been shown to be useful for understanding the effect of fire on plant physiology and mortality [2-4]. FRP can be retrieved remotely using single band radiance observations using approximations to Planck's law over a finite range of temperatures [5-7] and assuming clear observing conditions. Using this technique, Fisher et al. [5] derived and demonstrated a method for the remote retrieval of FRP from hot $(>1600 \mathrm{~K}$ ) gas flares using shortwave infrared (SWIR) $1.6 \mu \mathrm{m}$ and $2 \mu \mathrm{m}$ wavelength nighttime radiance observations, based on established [6,7] methods for relatively cooler (400-1000 K) wildfire FRP measurements, which use middle infrared (MIR) $4 \mu \mathrm{m}$ radiance observations. The effect of atmospheric smoke and aerosols, although known to attenuate $[6,8,9]$ the signal arriving at the sensor, are largely unconstrained, and have been assumed to be minimal [5,8,10-14] at longer visual wavelengths.

To the best of our knowledge, the attenuation of FRP by soot and dark smoke has not been systematically studied. Such studies are important to reduce the uncertainties in global greenhouse gas emission estimates from both biomass and gas flares. Further, FRP metrics can be used to estimate 
changes in net primary productivity (NPP) as an estimate of vegetation damage (i.e., burn severity) of wildfire and prescribed fire [3]. Monitoring burn severity using FRP instead of common spectral metrics (e.g., normalized burn ratio and derivatives), could result in better predictions of post-fire tree growth and damage for land managers [4]. Given reported increases in the number of severe wildfire events, particularly in the United States $[15,16]$, the application of FRP will likely continue to increase. If smoke and soot limitations to FRP are not addressed, estimates of ecophysical change could be biased.

The difficulty of obtaining independent reference data at the time of the satellite overpass makes the validation of active fire products challenging, because both wildland fires and atmospheric conditions change continuously in space and time $[17,18]$. Due to their well-constrained locations, active gas flares have been used for the characterization and accuracy assessments $[9,19]$ of active fire products. Gas flares are frequently detected by moderate spatial resolution satellite platforms, such as the $30 \mathrm{~m}$ Landsat [14] and $375 \mathrm{~m}$ Visible Infrared Imaging Radiometer Suite (VIIRS), as detection rates depend upon the relative size of the fire to the detection footprint. Coarse sensors, such as the $1 \mathrm{~km}$ Moderate Resolution Imaging Spectroradiometer (MODIS) satellite, detect relatively larger gas flares.

Recently, the news media (e.g., [20-22]) reported emergency oil and gas flaring over four oil fields near Abqaiq, Saudi Arabia. The extensive dark sooty smoke seen in satellite imagery since 14 September 2019 triggered environmental and health concerns. Media reports suggested that the dark smoke was the result of emergency flaring [13], an established method to safely dispose of the excess oil and gas that a plant cannot process. This event provided a unique opportunity to compare satellite observations before and during the emergency flaring to understand the effect of smoke and soot on remote FRP retrievals.

In this letter, we compare visual (VIS) to MIR wavelength observations retrieved from MODIS, VIIRS, and Landsat 8 satellites, which have different overpass times and nominal spatial resolutions ranging from $30 \mathrm{~m}$ to $1 \mathrm{~km}$, before and during emergency flaring. It is noted that gas flare FRP retrievals at $2 \mu \mathrm{m}$ are generally retrieved using nighttime observations [5,23]; however, we use the daytime observations to qualitatively illustrate the effect of dark smoke readily identified in daytime imagery. Higher $4 \mu \mathrm{m}$ FRP and $2 \mu \mathrm{m}$ observations were expected during the emergency flaring event compared to pre-flaring observations. We found that although the $4 \mu \mathrm{m}$ FRP measurements are higher than pre-flaring levels, the $2 \mu \mathrm{m}$ band observations are mostly lower. A high degree of variability in the $4 \mu \mathrm{m}$ FRP among the satellites also was seen. These results indicate that SWIR $\sim 2 \mu \mathrm{m}$ and shorter wavelength observations are impacted more by the presence of dark smoke and may underestimate gas FRP under sooty conditions. Dark, sooty smoke typically results from incomplete combustion, and can also appear over fires with limited oxygen supplies, such as in smoldering fires. Thus, understanding the effects of soot may help better constrain atmospheric emissions from such gas flares and wildland fires.

\section{Data and Methods}

\subsection{VIS- SWIR $2 \mu \mathrm{m}$ Data}

Landsat 8 is a polar-orbiting satellite that can image the globe in 11 spectral bands, ranging from reflective to emissive thermal wavelengths, at a spatial resolution of 30 and $100 \mathrm{~m}$, respectively, and includes a $15-\mathrm{m}$ panchromatic band. The Landsat 8 satellite has a revisit frequency of 16 days, with a required nominal equatorial crossing mean local time of 10:00 $\mathrm{AM} \pm 15 \mathrm{~min}$ [24]. The Landsat 8 onboard Operational Land Imager (OLI) instrument measures VIS-SWIR radiance/reflectance data in seven spectral bands, and is produced in approximately $185 \times 180 \mathrm{~km}$ tiles defined in a Worldwide Reference System (WRS-2) [24] of paths and rows. The most recent and available calibrated and terrain-corrected top of atmosphere L1T product includes Landsat $0.65 \mu \mathrm{m}$ band $4,0.56 \mu \mathrm{m}$ band 3, $0.48 \mu \mathrm{m}$ band 2 and $2.20 \mu \mathrm{m}$ band 7 reflectance.

Landsat 8 data acquisitions over the Saudi Arabia fires (WRS-2 path 164 and row(s) 043 and 042) that were acquired on the 1st and 17th of September, are used in this study for qualitative illustration 
only. Landsat 8 data were downloaded from the National Aeronautical and Space Administration (NASA) Land Processes Distributed Active Archive Center LPDAAC [25].

MODIS sensors on board the Aqua and Terra polar-orbiting platforms can map the Earth in 36 spectral bands, spanning reflective to thermal wavelengths, up to two times each day and night, with nominal overpass times at local 10:30 AM/PM and 1:30 AM/PM at the equator. MODIS Level-3 data are gridded in horizontal $(\mathrm{h})$ and vertical (v) tiles, and the 500-m reflectance data are available as the MYD09GA (Aqua) and MOD09GA (Terra) standard collection 6 products. These products include calibrated and gridded $500 \mathrm{~m} 2.13 \mu \mathrm{m}$ surface reflectance. Daily MODIS SWIR data from the 1st to the 21st of September were downloaded from the NASA Land Processes Distributed Active Archive Center (LPDAAC) [25].

\subsection{MIR 4 um FRP Data}

MODIS and VIIRS sensors also have the MIR $4 \mu \mathrm{m}$ band required to detect fires that are actively burning, and retrieve FRP at the time of overpass. The 375-m VIIRS sensor is on board the Suomi National Polar-Orbiting Partnership (Suomi NPP) spacecraft with equatorial over pass around local 1: 30 AM/PM. We use the VIIRS VNP14IMGTDL and collection 6 MODIS Level 3 Aqua (MYD14) and Terra (MYD14) satellite active fire products in this study. Each 375-m (VIIRS) or $1 \mathrm{~km}$ (MODIS at nadir) observation identifies whether an active fire was detected and retrieves the FRP in megawatts MW. Active fires are detected by their high and contrasting $4 \mu \mathrm{m}$ brightness temperatures compared to the neighboring pixels. A series of locally adaptive contextual tests using $4 \mu \mathrm{m}$ observations and other wavelengths are also used to reject false alarms. Once a fire pixel is detected, its FRP is derived using a linear relationship between the FRP and the $4 \mu \mathrm{m}$ radiance [7]. The contribution of non-burning background radiance to the FRP is minimized [6,7] by subtracting the background $4 \mu \mathrm{m}$ radiance from the fire pixel. Algorithms specific for MODIS [6,7] and VIRS [26] FRP have been developed using the MIR bands [6,7], and are being operationally used. Active fire data from both MODIS and VIIRS between the 1st September and 21st of September 2019 for MODIS tile h22; v06 was downloaded from the NASA Fire Information for Resource Management System (FIRMS) [27].

\subsection{Methods}

We compare the $2 \mu \mathrm{m}$ and $4 \mu \mathrm{m}$ satellite observations before and after the day of emergency flaring over the four oil fields at Abqaiq, Saudi Arabia, reported by [20-22]. A unique spatial extent box is conservatively defined for each of the four sites for analysis as the smallest rectangular extent that encompasses all central locations of active fire detections from both MODIS and VIIRS satellites over each site irrespective of the day or time of detection between the 1st and 21st of September 2019. The smallest rectangular box enables a consistent spatial extent for analysis on all days spanning before and during emergency flaring. Daily time series summaries of $2 \mu \mathrm{m}$ and $4 \mu \mathrm{m}$ satellite observations over each flare specific extents are presented and discussed. Coherent increases and decreases in observations across SWIR and MIR wavelengths are highlighted and discussed considering the influence of dark, sooty smoke.

\section{Results}

Thick, black smoke emanating from the emergency oil gas flaring sites not visible on the 1st of September 2019 is evident in the Landsat 8 images in both VIS and SWIR band 7 reflectance (Figure 1) over four locations in the image acquired on 17th September 2019. The SWIR band is not totally immune to the spectrally disruptive effects of thick, black smoke, although it is known to be less sensitive to smoke and aerosols compared to visible wavelengths. 

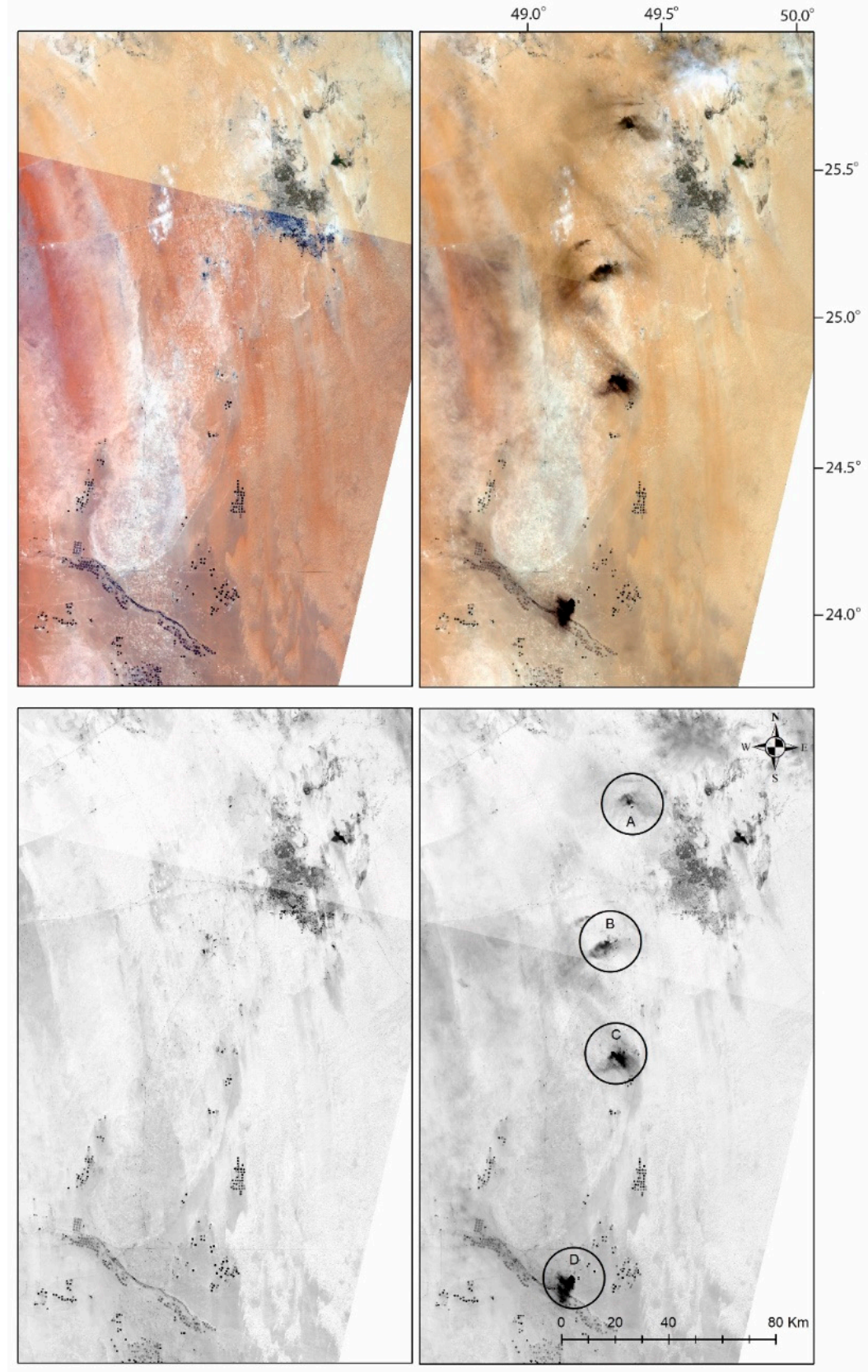

Figure 1. Landsat 8 True color $(0.65 \mu \mathrm{m}$ band 4 as Red, $0.56 \mu \mathrm{m}$ band 3 as Green and $0.48 \mu \mathrm{m}$ band 2 as Blue) acquisition over the four (A-D) Saudi Arabia flares before (1st September 2019 top left) and after (17th September 2019 top right) the reported emergency flaring on 14th September 2019 are illustrated. The Landsat $2.2 \mu \mathrm{m}$ band 7 reflectance before and after are also illustrated (bottom images). Thick, black smoke is evident in the images of 17th September 2019 in both visual and SWIR wavelengths.

To investigate the effect of soot and smoke further, the active fire detections in a time period that encompassed the day of flaring were examined. Figure 2 illustrates the active fire detection locations by VIIRS and both MODIS Aqua and Terra platforms between the 1st and the 21st of September. The background image in Figure 2 is from the 17th of September. It is clear each site may have multiple gas flares, and that smoke can reduce the observed reflectance, and may even obscure gas flares. To study the effect of smoke on FRP, the time series of FRP retrievals is examined. 

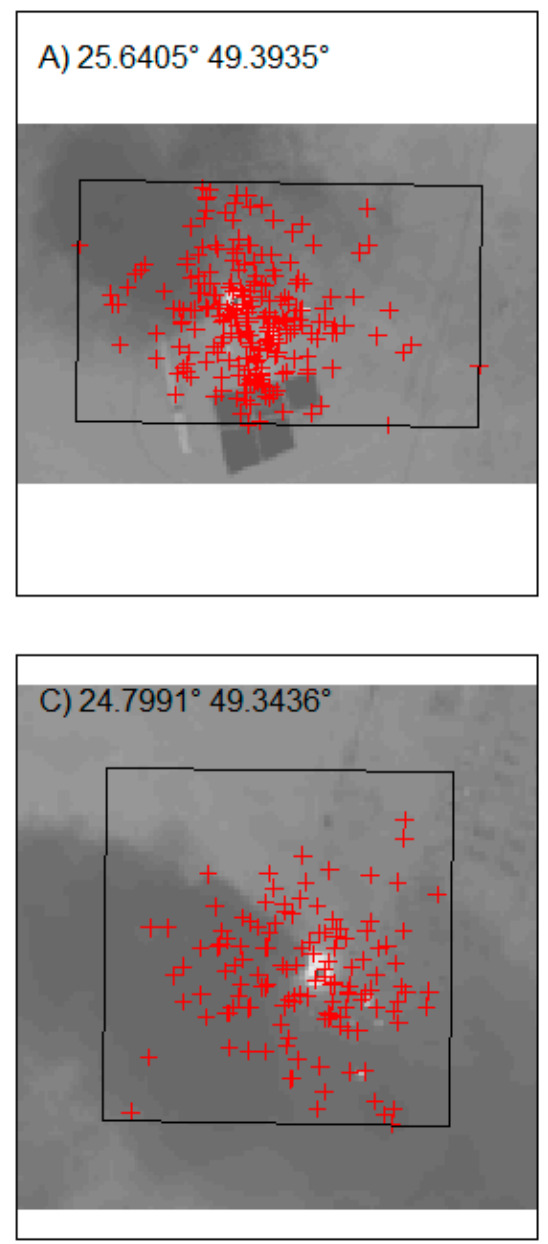

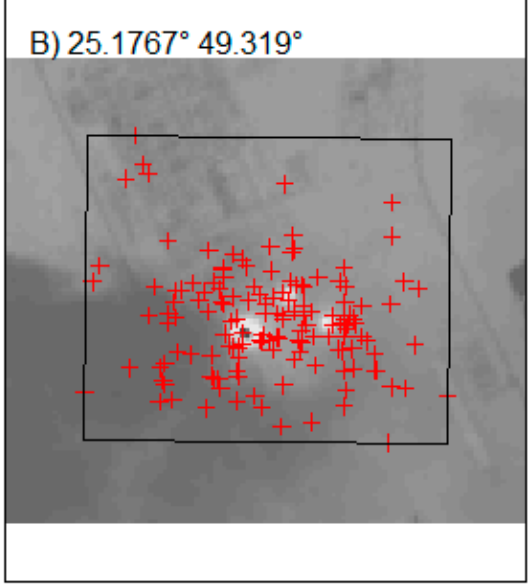

\section{D) $24.0403^{\circ} 49.2^{\circ}$}

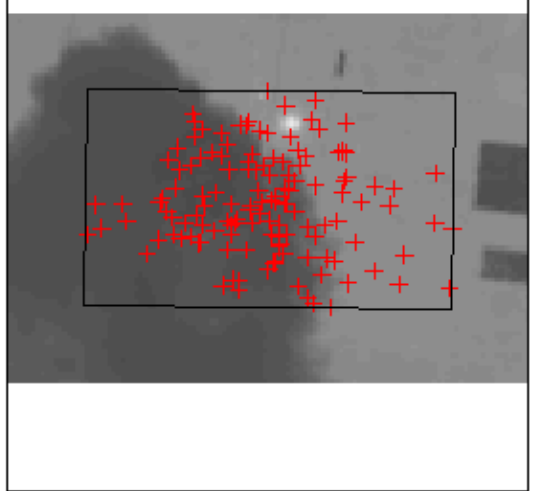

Figure 2. Active fire detection locations from Moderate Resolution Imaging Spectroradiometer (MODIS) Aqua, Terra and Visible Infrared Imaging Radiometer Suite (VIIRS) are shown as red crosses over the four (A-D) flares illustrated in Figure 1. Central geographic coordinates are shown for each flare site illustrated in Figure 1 is also shown in each frame. The black box is the smallest spatial extent that encompasses all detections in the study period. Background Landsat $82.2 \mu \mathrm{m}$ band 7 reflectance over the extents padded by $1 \mathrm{~km}$ is shown to provide spatial context.

Figure 3 summarizes the time series of FRP as observed over the four distinct emergency flaring locations. VIIRS detected active fires over these locations on most days before 14th September 2019, while MODIS detections are predominantly after the flaring. This is expected, as detection probabilities are proportional to the fractional area covered by fire with respect to the pixel footprint.

Hence, the smaller (375-m) pixel dimension of VIIRS has increased the probabilities of detection as compared to MODIS $1 \mathrm{~km}$. FRP retrieved from both MODIS Aqua and Terra and VIIRS are summarized as box and whisker plots in Figure 3. A distinct increase in the FRP is seen after the 14th of September 2019 over all sites by all satellites as compared to pre-flare FRP, which is expected due to continued active flaring at least until the end of the study period, which was the 21st of September, 2019. It is also evident that the three satellite observations differ considerably over these four locations during the time of emergency flaring. Although the gas stacks themselves cover a small fraction of the MODIS and VIIRS pixels, flame size, atmospheric effects and sensor characteristics such as the point spread function can all influence the possibility of detections over multiple [9] pixels for the same subpixel fire. Different sensors, overpass times, view angle and atmospheric effects can influence FRP retrievals. 

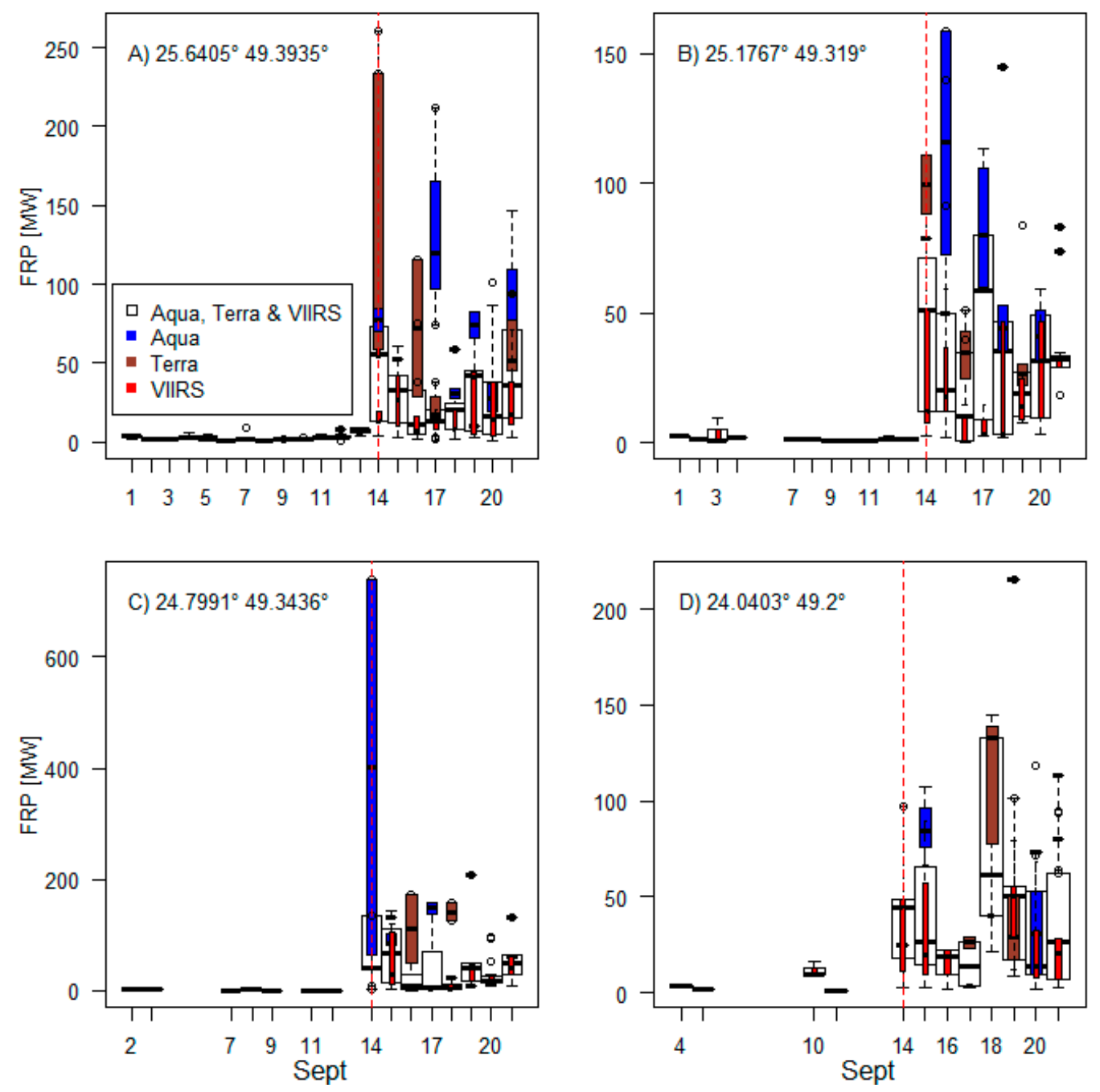

Figure 3. Time series of $4 \mu \mathrm{m}$ fire radiative power (FRP) retrieval from three satellites is summarized as whisker plots for the four (A-D) flares illustrated in each frame of Figure 1. Central geographic coordinates are shown for each flare site illustrated in Figure 1 is also shown in each frame. The mean is boxed by the 75th and 25th percentiles. MODIS Terra and Aqua are identified as brown and blue box and whisker plots, respectively, and VIIRS is shown as red. Open box summaries include all observations from all three satellites. The vertical dashed red line marks the day of emergency flaring. Different satellites with different overpass times have different FRP retrievals after the day of flaring and highlights the ephemeral and changing conditions at the flare site.

The increased FRP is highly variable with distinct decreases relative to FRP on the 14th of September on certain dates, specifically on the 16th and on the 21st of September over all sites. The increase in FRP was expected after the emergency flaring, but the decrease on certain days can be explained only if flare rates were all simultaneously reduced on all four specific sites, or if they had similar viewing conditions that resulted in reporting reduced FRP. To investigate this further, the daily $2 \mu \mathrm{m}$ observations over the sites for the same four locations were analyzed.

Figure 4 summarizes the observed MODIS Aqua and Terra $2.13 \mu \mathrm{m}$ reflectance over the flaring sites, irrespective of the day or time of detection between the 1st and the 21st of September 2019. Significant increase in $4 \mu \mathrm{m}$ FRP and $2 \mu \mathrm{m}$ reflectance over the flare is expected if the effect of smoke was negligible. However, it is evident that $2 \mu \mathrm{m}$ reflectances are mostly low, with very few isolated observations that were higher on certain days than pre-emergency flaring days (Figure 4). The low $2 \mu \mathrm{m}$ reflectance values strongly suggest the attenuating effect of dark smoke. On the 17th and 21st of September, the reflectance values are all lower, thereby corresponding with the lows in FRP (Figure 3). 
This simultaneous decrease in signal can happen if the flaring rate was decreased on those days, or can be an artifact of dark smoke. The Landsat 8 image (Figures 1 and 2) on the 17th of September 2019 clearly indicates heavy, thick smoke and continued flaring, which strongly suggests that the attenuation of FRP and the $2 \mu \mathrm{m}$ observations result from sooty smoke. The presence of soot and subsequent lowering of the $2 \mu \mathrm{m}$ reflectance continue to be observed (Figure 4 ) after the flare date and throughout the study period. The lowering of fire signal in a pixel during the day time is the result of dark smoke obscuring both the fire and adjacent non-burning land in the pixel footprint. However, during nighttime, dark smoke obscuring of the flame may lead to an attenuation of the signal and hence the inferred FRP.
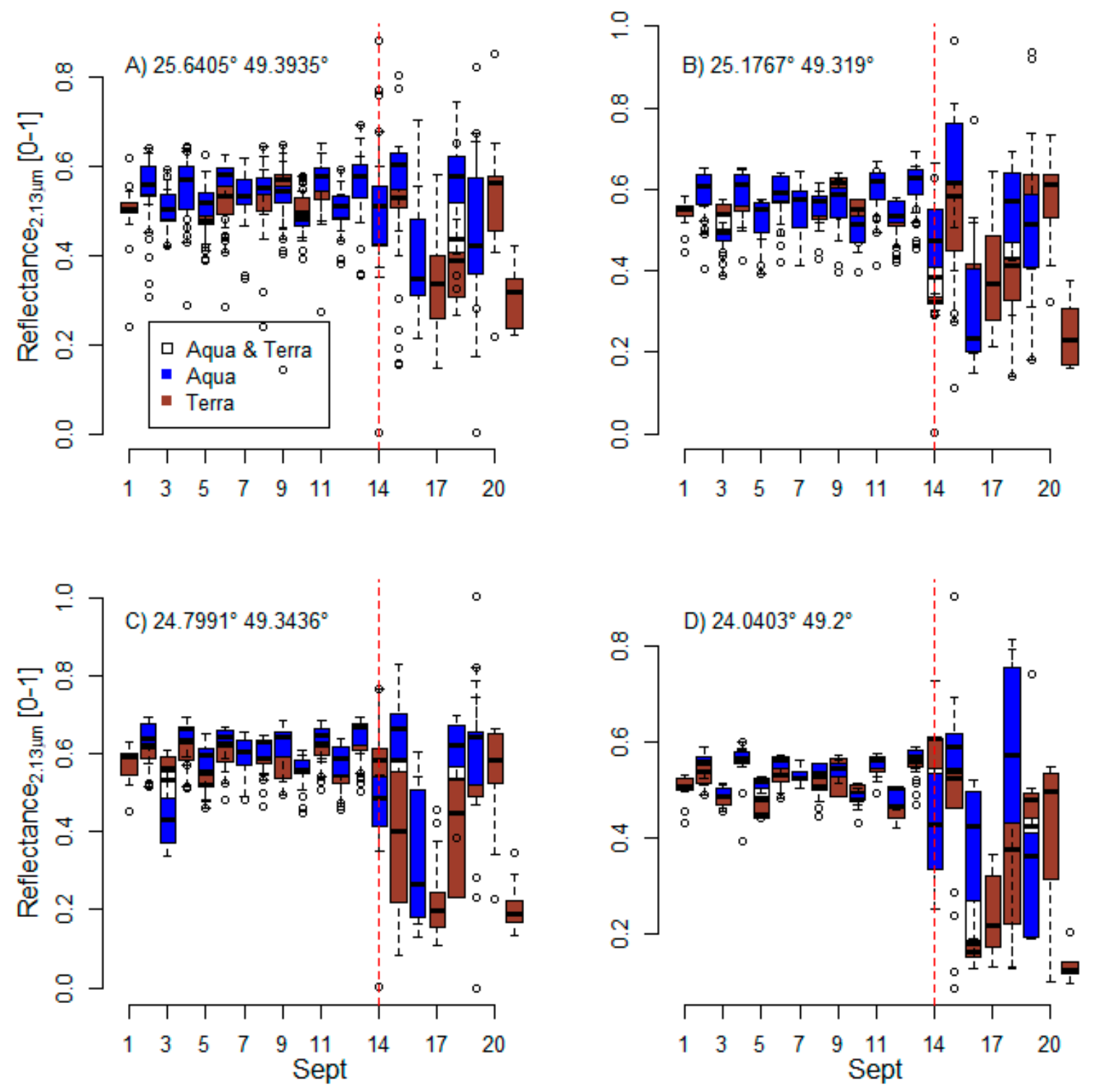

Figure 4. Time series of $2.13 \mu \mathrm{m}$ (MODIS band 7) reflectance from MODIS Terra (brown) and Aqua (blue) platforms summarized as whisker plots for the four (A-D) flares illustrated in each frame of Figure 1. Central geographic coordinates are shown for each flare site illustrated in Figure 1 is also shown in each frame. The mean is boxed by the 75 th and 25 th percentiles. The vertical red dashed line marks the day of emergency flaring. Different satellites with different overpass times have similar reflectance before the day of flaring, while they are different and mostly lower after the day of emergency flaring. Central geographic coordinates shown for each flare illustrated in Figure 1 are also shown in each frame. 


\section{Conclusions}

We compared the MIR $4 \mu \mathrm{m}$ FRP observations from MODIS, VIIRS, before and during the emergency flaring alongside the SWIR $2 \mu \mathrm{m}$ observations using daily MODIS Aqua and Terra and available Landsat 8 observations. We show that the presence of smoke can lower $4 \mu \mathrm{m}$ FRP retrievals and $2 \mu \mathrm{m}$ signals, especially over emergency flaring gas sites that produce dark smoke. These results suggest that global remote sensing-based gas flare inventorying programs may potentially underestimate emissions [5,23]. Given that a variety of factors may lead to emergency oil and gas flaring, and that emergency flaring may not always be reported [13], it is important to consider the possibility of flares going under-reported or undetected through current remote sensing methods.

The production of dark smoke is usually an indicator of incomplete combustion in gas flares, as well as in wildland fires with an inadequate oxygen supply (i.e., smoldering fires). Smoldering fires are the most emissive and have the lowest probability of detection [14,17] due to smoke and lower temperatures. Global gas flaring inventory $[13,23]$ methodologies and wildfire monitoring need to recognize consider that soot can lower detection rates and underestimate FRP retrievals. Sooty gas flares may be identified by monitoring the $4 \mu \mathrm{m}$ FRP, which is affected less by smoke and soot. Smoke obscuration is an issue for remote wildland fire detections using satellites [9,18] as well. Future studies can advance this work by exploring the use of wavelengths longer than MIR to flag smoky observations and constrain emissions from smoldering fires. Laboratory studies may help identify methodologies for the detection and quantification of FRP underestimation resulting from soot, as well. The growing number of sensors with active fire capabilities exploiting different spectral and temporal observations should also help constrain the effect of smoke for both gas flares and wildland fires.

Author Contributions: S.S.K. and J.H. conceived the idea, S.S.K. wrote the original manuscript with inputs from J.P. and B.P. All authors have read and agreed to the published version of the manuscript.

Funding: This research received no external funding.

Acknowledgments: We thank the two anonymous reviewers whose comments and suggestions greatly improved our manuscript. This work was performed under U.S. Geological Survey (USGS) contract \#140G0119C0001. All of the data used in this study were obtained from public domains and are freely available. We acknowledge the use of data and imagery from LANCE FIRMS operated by NASA's Earth Science Data and Information System (ESDIS) with funding provided by NASA. Any use of trade, firm, or product names is for descriptive purposes only and does not imply endorsement by the US Government.

Conflicts of Interest: The authors declare no conflict of interest. The funders had no role in the design of the study; in the collection, analyses, or interpretation of data; in the writing of the manuscript, or in the decision to publish the results.

\section{References}

1. Crutzen, P.J.; Andreae, M.O. Biomass burning in the tropics: Impact on atmospheric chemistry and biogeochemical cycles. Science 1990, 250, 1669-1678. [CrossRef] [PubMed]

2. Smith, A.M.; Talhelm, A.F.; Johnson, D.M.; Sparks, A.M.; Kolden, C.A.; Yedinak, K.M.; Apostol, K.G.; Tinkham, W.T.; Abatzoglou, J.T.; Lutz, J.A. Effects of fire radiative energy density dose on Pinus contorta and Larix occidentalis seedling physiology and mortality. Int. J. Wildland Fire 2017, 26, 82-94. [CrossRef]

3. Sparks, A.M.; Kolden, C.A.; Smith, A.M.; Boschetti, L.; Johnson, D.M.; Cochrane, M.A. Fire intensity impacts on post-fire temperate coniferous forest net primary productivity. Biogeosciences 2018, 15, 1173. [CrossRef]

4. Kolden, C.; Sparks, A. Towards Improved Quantification and Prediction of Post-Fire Recovery in Conifers: Expanding Laboratory Fire Radiative Energy-Tree Physiology Experiments to a Mature Forest Stand. Final Report Joint Fire Science Project 16-2-01-9; Boise, ID; 2018; pp. 1-18. Available online: https: //www.firescience.gov/projects/16-2-01-9/project/16-2-01-9_final_report.pdf (accessed on 26 September 2019).

5. Fisher, D.; Wooster, M. Shortwave IR Adaption of the Mid-Infrared Radiance Method of Fire Radiative Power (FRP) Retrieval for Assessing Industrial Gas Flaring Output. Remote Sens. 2018, 10, 305. [CrossRef]

6. Kaufman, Y.J.; Justice, C.; Flynn, L.; Kendall, J.; Giglio, L.; Prins, E.; Ward, D.; Menzel, P.; Setzer, A. Monitoring global fires from EOS-MODIS. J. Geophys. Res. 1998, 103, 215-239. [CrossRef] 
7. Wooster, M.J.; Roberts, G.; Perry, G.; Kaufman, Y. Retrieval of biomass combustion rates and totals from fire radiative power observations: FRP derivation and calibration relationships between biomass consumption and fire radiative energy release. J. Geophys. Res. Atmos. 2005, 110. [CrossRef]

8. Oliva, P.; Schroeder, W. Atmospheric correction of VIIRS and MODIS fire radiative power retrievals for multi-sensor comparison. In Proceedings of the IEEE International Geoscience and Remote Sensing Symposium (IGARSS), Milan, Italy, 26-31 July 2015; pp. 2038-2040.

9. Kumar, S.S.; Picotte, J.J.; Peterson, B. Prototype Downscaling Algorithm for MODIS Satellite $1 \mathrm{~km}$ Daytime Active Fire Detections. Fire 2019, 2, 29. [CrossRef]

10. Wooster, M.J.; Roberts, G.; Smith, A.M.; Johnston, J.; Freeborn, P.; Amici, S.; Hudak, A.T. Thermal remote sensing of active vegetation fires and biomass burning events. In Thermal Infrared Remote Sensing; Springer: Dordrecht, Germany, 2013; pp. 347-390.

11. Wooster, M.; Zhukov, B.; Oertel, D. Fire radiative energy for quantitative study of biomass burning: Derivation from the BIRD experimental satellite and comparison to MODIS fire products. Remote Sens. Environ. 2003, 86, 83-107. [CrossRef]

12. Smith, A.M.; Wooster, M.J. Remote classification of head and backfire types from MODIS fire radiative power and smoke plume observations. Int. J. Wildland Fire 2005, 14, 249-254. [CrossRef]

13. Elvidge, C.; Zhizhin, M.; Baugh, K.; Hsu, F.-C.; Ghosh, T. Methods for global survey of natural gas flaring from visible infrared imaging radiometer suite data. Energies 2016, 9, 14. [CrossRef]

14. Kumar, S.S.; Roy, D.P. Global operational land imager Landsat-8 reflectance-based active fire detection algorithm. Int. J. Digit. Earth 2018, 11, 154-178. [CrossRef]

15. Barbero, R.; Abatzoglou, J.T.; Larkin, N.; Kolden, C.; Stocks, B. Climate change presents increased potential for very large fires in the contiguous United States. Int. J. Wildland Fire 2015, 24, 892-899. [CrossRef]

16. Dennison, P.E.; Brewer, S.C.; Arnold, J.D.; Moritz, M.A. Large wildfire trends in the western United States, 1984-2011. Geophys. Res. Lett. 2014, 41, 2928-2933. [CrossRef]

17. Giglio, L.; Csiszar, I.; Restás, Á.; Morisette, J.T.; Schroeder, W.; Morton, D.; Justice, C.O. Active fire detection and characterization with the advanced spaceborne thermal emission and reflection radiometer (ASTER). Remote Sens. Environ. 2008, 112, 3055-3063. [CrossRef]

18. Schroeder, W.; Prins, E.; Giglio, L.; Csiszar, I.; Schmidt, C.; Morisette, J.; Morton, D. Validation of GOES and MODIS active fire detection products using ASTER and ETM+ data. Remote Sens. Environ. 2008, 112, 2711-2726. [CrossRef]

19. Morton, D.; Defries, R.; Randerson, J.; Giglio, L.; Schroeder, W.; Van Der Werf, G. Agricultural intensification increases deforestation fire activity in Amazonia. Glob. Chang. Biol. 2008, 14, 2262-2275. [CrossRef]

20. Gambrell, J. Saudi Arabia: Drone Attacks Knocked Out Half Its Oil Supply. Available online: https: //www.apnews.com/d20f80188e3543bfb36d512df7777cd4 (accessed on 26 September 2019).

21. Mosley, T. Attacks on Saudi Oil Plant Carry Heavy Environmental Cost. Available online: https://www.wbur. org/hereandnow/2019/09/19/saudi-oil-attacks-environment (accessed on 26 September 2019).

22. Bloomberg. Available online: https:/www.bloomberg.com/news/articles/2019-09-15/saudis-race-to-restoreoil-output-after-crippling-aramco-attack (accessed on 26 September 2019).

23. Fisher, D.; Wooster, M.J. Multi-decade global gas flaring change inventoried using the ATSR-1, ATSR-2, AATSR and SLSTR data records. Remote Sens. Environ. 2019, 232, 111298. [CrossRef]

24. Loveland, T.R.; Dwyer, J.L. Landsat: Building a strong future. Remote Sens. Environ. 2012, 122, $22-29$. [CrossRef]

25. EARTHDATA. Available online: https://earthdata.nasa.gov/ (accessed on 26 September 2019).

26. Schroeder, W.; Oliva, P.; Giglio, L.; Csiszar, I.A. The New VIIRS $375 \mathrm{~m}$ active fire detection data product: Algorithm description and initial assessment. Remote Sens. Environ. 2014, 143, 85-96. [CrossRef]

27. FIRMS. Available online: https://earthdata.nasa.gov/earth-observation-data/near-real-time/firms (accessed on 26 September 2019).

(C) 2020 by the authors. Licensee MDPI, Basel, Switzerland. This article is an open access article distributed under the terms and conditions of the Creative Commons Attribution (CC BY) license (http://creativecommons.org/licenses/by/4.0/). 